\title{
Spectral sensitivity in the photodegradation of fir wood (Abies alba Mill.) surfaces: colour changes in natural weathering
}

\author{
Vjekoslav Živković • Martin Arnold • \\ Kristijan Radmanović • Klaus Richter • \\ Hrvoje Turkulin
}

Received: 6 November 2012/Published online: 15 November 2013

(C) The Author(s) 2013. This article is published with open access at Springerlink.com

\begin{abstract}
Activation spectra of wood under natural irradiation were investigated in detail in this work. The main purpose was to study colour changes on the wood surface over time and into the depth during natural light exposure and thus to further contribute to the optimization of surface-protecting treatments. In a natural weathering test, three 80 - $\mu \mathrm{m}$-thick strips of fir wood forming the surface layer of a wood composite were exposed to light under a series of glass cut-off filters. Samples were withdrawn at intervals and tested for colour changes. Identification of the most detrimental wavebands of light causing photodegradation was performed based on recorded colour changes. With chronological development of exposure, the colour changes shifted ever deeper into the surface and further into the visible region of the spectrum. A relatively narrow waveband from 360 to $435 \mathrm{~nm}$ was identified in the activation spectra to be the most active band, causing the greatest proportion of recorded colour changes. However, also visible light of wavelengths up to $515 \mathrm{~nm}$ significantly contributed to colour changes of the surface layers.
\end{abstract}

\footnotetext{
V. Živković $(\bowtie) \cdot$ K. Radmanović $\cdot$ H. Turkulin Department of Furniture and Wood Products, Faculty of Forestry, University of Zagreb, Svetošimunska 25, 10000 Zagreb, Croatia

e-mail: zivkovic@sumfak.hr

M. Arnold

Applied Wood Materials, Empa, Swiss Federal Laboratories for Materials Science and Technology, 8600 Dübendorf, Switzerland

K. Richter

Lehrstuhl für Holzwissenschaft, Holzforschung München, Technische Universität München, Winzererstr. 45, 80797 München, Germany
} 


\section{Introduction}

Wood protected with clear or lightly pigmented coatings generally has limited surface durability outdoors. Shorter wavelengths of the light spectrum are associated with higher photon energies, particularly those in the ultraviolet (UV) portion of incident light: UVB $(280-315 \mathrm{~nm})$ and UVA $(315-400 \mathrm{~nm})$ have greater potential to break chemical bonds and are therefore generally regarded as most responsible for weathering degradation (Jacques 2000; Scott 2001). Even though past research gave answers to many questions, present knowledge of wavelength sensitivity of wood surface is still insufficient. Particularly, the identification of wavelengths of ultraviolet and visible light during natural weathering that cause changes in colour (as the first undesirable effect of weathering) was chosen to be of principal interest in this research. Identifying the most detrimental wavebands of light causing photodegradation (activation spectra) would enable both better understanding of the mechanisms of photodegradation and effective formulation of photostabilization techniques.

Activation spectra can be determined by the cut-off filter method using glass optical filters to cut off the lower end of the radiation below a specified wavelength. An alternative is a spectrographic technique with the advantage of better resolution obtained by a prism that separates radiation bands of wavelengths into very narrow, isolated spectral portions. The fact that there is no other radiation present except the one transmitted through the prism eliminates any possible synergistic or antagonistic interactions of different wavelength regions (Suttie 2006) or other natural influences (temperature, humidity, liquid water). Due to the small specimen sizes used to spectrographically determine the wavelength sensitivity, property changes are limited to those that can be measured on rather small surfaces (ASTM G178-09). On the other hand, the filter technique generally better reflects the conditions of natural exposure since it allows insights into the interaction of the effects of the spectral bands of interest with those of other wavelengths. The larger size of filters and thus specimen area enable identification of the most detrimental wavelengths by monitoring multiple properties during photodegradation. These include colour changes, chemical changes revealed by different spectroscopic techniques, weight loss, gloss reduction, checking, and mechanical properties such as increase in brittleness or loss in tensile strength or changes of any other properties that may contribute to the determination of the nature of degradation of any polymer (Andrady et al. 1992, 1996; Hu 1998, 1997; Kämpf et al. 1991; Andrady and Searle 1995; Evans et al. 2008). The data presented on waveband basis are specific to the light source used in the experiment and to the absorption spectrum of the material (Andrady 1997; Andrady et al. 1992). This means that not all commercially available artificial light sources would give results of equal reliability, but that a closer match of the absorption spectrum of light absorbers to the activation spectrum of a material should enable a more effective light protection.

In addition to the general belief that the UV portion of light is the main factor causing photodegradation, several attempts have been made to identify the most influential wavelengths of UV and visible light and to define activation spectra of wood. 
Exposures of wood powders to mercury light filtered by glass filters pointed out that the waveband between 305 and $385 \mathrm{~nm}$ is the most responsible one for yellowing (Sandermann and Schlumbom 1962a). However, it was later demonstrated that $\sim 80 \%$ of a mercury lamp's irradiance is in UV-C, UV-B, and UV-A spectral region (Tolvaj and Mitsui 2010), which renders it a strong UV light emitter that causes rapid and intensive degradation which is not characteristic of objects on earth surface. Derbyshire and Miller (1981) reported that wood will degrade outdoors at about half the rate when exposed only to wavelengths longer than $400 \mathrm{~nm}$ compared to the full solar spectrum (UV included), whereas Suttie (2006) reported that $30 \%$ of all colour changes $\left(\Delta \mathrm{E}^{*}\right)$ for Scots pine and spruce wood exposed to xenon light were due to the $450-700 \mathrm{~nm}$ radiation window. The dominating factor in the photodegradation process during summer is sunlight, for its effect causes a $70 \%$ reduction in tensile strength of spruce microsections. During winter, when irradiation is low, the increased amount of sulphur dioxide in the air was recorded to cause a $30 \%$ reduction in tensile strength (Raczkowski 1980).

Narrow band gaps $(20 \mathrm{~nm})$ of monochromatic light in the range of 246-496 nm were also employed to determine the most active wavelengths causing photodegradation of sugi earlywood (Kataoka et al. 2007). The depth of photodegradation was found to increase with wavelength up to and including the violet region $(403 \mathrm{~nm})$ of the visible spectrum. Blue light $(434-496 \mathrm{~nm})$ penetrated wood even deeper and was capable of bleaching the wood, but it did not significantly modify lignin; hence, it was regarded as not responsible for subsurface photodegradation. However, the study by Kataoka et al. (2007) excluded the influence of other elements present in natural conditions (temperature, humidity, precipitation) and the influence of broader wavelengths to surface changes over time of exposure. Visible light was also found to cause bleaching of acetylated spruce in natural weathering, but without modifying IR spectra of lignin (Mitsui 2010). Some experiments yielded even unexpected results. Chang et al. $(1999,2000)$ demonstrated that the colour changes of sugi heartwood gradually decreased with increasing wavelength in the range $280-450 \mathrm{~nm}$, but they increased when wood was exposed to wavelengths longer than $600 \mathrm{~nm}$.

Development of surface checks is also found to be wavelength-dependent. Evans et al. (2008) demonstrated that samples shielded from light of lower (but more energetic) wavelengths developed less checking and suffered less delignification compared to samples exposed to the full solar spectrum.

The experiment of the current study was based on the so-called thin strip method. This technique consists of the preparation (by microtoming) of a number of thin wood sections that are exposed to light and environmental conditions, and subsequently subjected to various property measurements. The basics of the method as well as dimensions of the thin strips were adopted from an earlier work by Turkulin (1996; Turkulin et al. 2006), who refined the method developed by Raczkowski (1980), Derbyshire and Miller (1981), and Evans (1988).

As can be seen from this overview, different approaches to detecting activation spectra of wood involving different radiation sources, wood species, and testing methodologies yielded many valuable results, but gave no detailed answer regarding the chronological development of spectral sensitivity of wood surfaces in natural 
conditions. The main purpose of this work was to identify the wavelength bands causing major colour changes on the wood surface during natural light exposure. The results presented here should further contribute to the understanding of photodegradation processes and help in improving protective systems.

\section{Materials and methods}

Material preparation

\section{Thin wood strips}

Rectangular fir wood (Abies alba Mill.) blocks were selected to be straight-grained, free from all visible defects, machined, and smooth-planed. Typical block for sectioning, by means of density, ring width, and latewood portion, consisted of 4-5 rings per $10 \mathrm{~mm}$ width. Blocks were chosen to be adjacent in longitudinal direction (prepared from the same stick) to minimize differences in density, number, and overall width of annual rings and proportion of latewood that could influence the results. Blocks with nominal dimensions of $100 \mathrm{~mm} \times 40 \mathrm{~mm} \times 10 \mathrm{~mm}$ (longitudinal, tangential, and radial direction) were vacuum impregnated with distilled water until fully saturated. Afterwards, they were microtomed with a conventional sliding microtome, using knives with exchangeable blades to give $80-\mu \mathrm{m}$-thick strips. The cutting plane was inclined at approximately $5^{\circ}$ to the radial plane to avoid the rays appearing as transversal lines across the strip face. Further details of microtoming technique can be found elsewhere (e.g. Raczkowski 1980; Derbyshire and Miller 1981; Evans 1988; Turkulin 1996; Turkulin and Sell 2001). Dried strips were collected in the order of slicing to produce batches of 3 strips whose earlywood and latewood zones matched perfectly to represent an approximately $240 \mu \mathrm{m}$ thick surface assembly. The reason for having strips batched in 3 layers was to monitor changes in photodegradation as a depth profile over the exposure period. After drying (20 h at $20{ }^{\circ} \mathrm{C}$ and $60 \%$ relative humidity), thickness of the strips was monitored with an electronic thickness gauge (reading accuracy $\pm 0.1 \mu \mathrm{m}$ ) along the strip length. To avoid incorrect readings due to the excessive pressure of the gauge tip to the wood strips (which could cause deformations, especially on earlywood bands), the surface of the tip was chosen to be spherical $(\varnothing 7 \mathrm{~mm})$ and a gauge type was chosen, which exerts a minimum force on the tip $(\sim 0.55 \mathrm{~N})$. All the strips that did not fall into the range of $\pm 5 \%$ of nominal thickness were rejected. However, only about $10 \%$ of the radial strips fell out of the range of $\pm 4 \mu \mathrm{m}$ of nominal value, which indicated that the microtoming was performed correctly. To obtain a sufficient number of strips for a series of trials, it was necessary to section five blocks. Each batch consisted of five replicate packs of (3) strips, each from a different block.

\section{Glass filters and cassettes}

A set of 13 cut-off glass filters were used to produce narrow bands of the light spectrum in the wavelength range from 295 to $515 \mathrm{~nm}$. Spectral transmission 
curves of the filters are presented in Fig. 2. Aluminium foil was used as an additional "filter" that prevented any light from reaching the wood surface, but allowed the action of all other exposure factors (variation of moisture and temperature). Each filter covered a batch of 5 replicate packs of (3) strips. Any two successive filters created a difference in transmission which is defined as a spectral band representing the decremental portion of the light blocked by the shorter wavelength filter of the pair. The spectral regions of irradiation (band pass) in UV and visible region are defined by the differences in transmissions of pairs of filters (Fig. 2, right). The areas under the curves in Fig. 2 present the light to which the samples under the particular filter were specifically exposed to, and the samples under the first "upper" filter were not exposed to. The main purpose of using cut-off filters was to get an indication on how intensively each of these regions affected the colour stability and to enable the calculation of activation spectra.

The experimental setup was created with the intention of exposing the specimens to filtered light and at the same time to environmental conditions. For that purpose, special stainless steel cassettes were designed (Fig. 1). The strips were attached to aluminium frames using a double-sided adhesive tape. Afterwards, the frames with the attached specimens were placed behind glass filters that were sealed with rubber gaskets to the sample holder to avoid liquid water ingress to the strips. Frames with specimens were tightly backed with a 2-mm-thick fir veneer, whose purpose was to hygroscopically link to the environmental conditions. The ends of the cassettes remained open to create a slot for ventilation along the backside of the veneers, thus enabling air circulation and moistening of the specimens. This setup enabled the light to reach the strips only through the glass filter at the front, but also prevented the rain to remove soluble degradation products.

\section{Natural weathering}

Natural weathering was performed between mid-May and mid-August in order to expose the samples to maximum solar energy. The cassettes with the strips were placed on the racks for natural exposure at $45^{\circ}$ to the horizontal facing south at Empa (Swiss Federal Laboratories for Materials Science and Technology) in Dübendorf, Switzerland. The site is continental, semi-urban and situated at $47^{\circ} 25^{\prime} \mathrm{N}$ $8^{\circ} 37^{\prime} \mathrm{E}, 440 \mathrm{~m}$ above sea level. Weather conditions during weathering were as follows: temperature from 4 to $35^{\circ} \mathrm{C}$ and relative humidity from 20 to $99 \%$. During the 90 days of weathering, a data logger was placed in the ventilation slot behind the strips to record temperature and relative humidity. The results of these measurements were compared with the moisture content of the backing veneers, determined gravimetrically. These measurements showed that the backing veneers changed their moisture content swiftly and reacted to exterior climatic conditions during natural exposure. Moisture content of backing veneers varied between 5.5 and $19.5 \%$, depending on the time of day, temperature, relative humidity, and precipitation. Strips were withdrawn after 12, 30, 60, and 90 days of exposure and subjected to measurements. 
Fig. 1 Assembled cassette with wood strips behind glass. The chosen construction of the cassette enabled the strips to be exposed to light only through a glass filter. The ends of the cassettes remained open to enable hygroscopical moistening of the strips from the backside

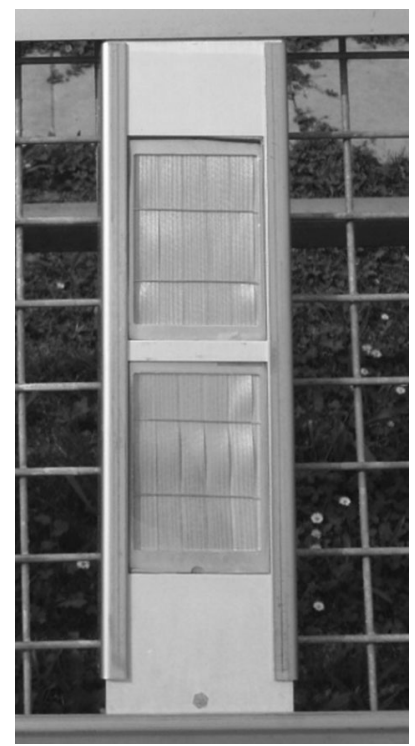

\section{Colour measurements and calculations}

Colour measurements were performed on the individual strips placed on a pad of white filter paper as a substrate. These measurements were used to quantify the colour changes in various surface layers and to assess the depth of light penetration. Colour changes during weathering were determined by two measurements in the middle of each strip — once prior to weathering and then after exposure. Prior to the measurements after exposure, the strips were conditioned for $6 \mathrm{~h}$ in laboratory atmosphere $\left(20{ }^{\circ} \mathrm{C}, 60 \%\right.$ relative humidity). The results of colour measurements are collected as full reflectance data from 360 to $740 \mathrm{~nm}$ using a portable spectrophotometer and accompanying software. The reflectance values were taken at every $10 \mathrm{~nm}$ across the range using the D65 standard illumination at $10^{\circ}$ standard observation and illumination area $\varnothing 11 \mathrm{~mm}$. Along with the reflectance data, CIE$\mathrm{L}^{*} \mathrm{a} \mathrm{b}^{*}$ system values were obtained. Colour changes were expressed as $\Delta \mathrm{E}^{*}$ according to the following formula: $\Delta E^{*}=\sqrt{\Delta L^{* 2}+\Delta a^{* 2}+\Delta b^{* 2}}$.

\section{Calculation of activation spectra}

Activation spectra were calculated for colour changes according to the following procedure, basically presented in ASTM G178-09.

1. Changes in $\%$ transmittance data for consecutive filters were calculated by subtracting the $\%$ transmittance of the longer wavelength cut-off (e.g. SF 12 $360 \mathrm{~nm}$ ) from that of the next shorter wavelength cut-off filter (e.g. F9 335, shaded area in Fig. 2, left). The obtained values were then plotted versus wavelength on a linear graph for each filter pair (shaded area Fig. 2, right). 

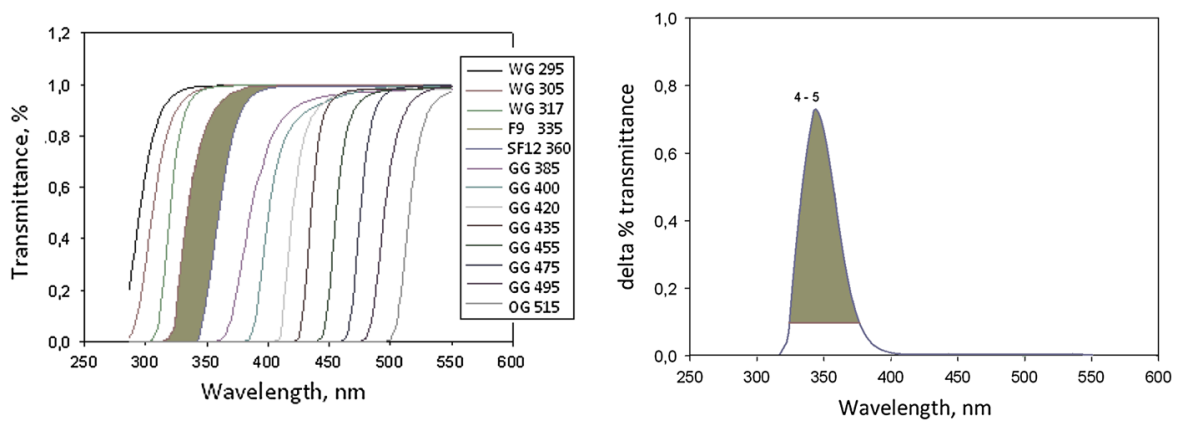

Fig. 2 Transmittance curves of cut-off UV/VIS filters of the set used in the experiment (left) and delta transmittance for a pair of successive filters (right). Changes in \% transmittance values were used to determine normalization factors necessary for calculation of activation spectra

2. Areas of spectral bands above $10 \%$ transmittance (shaded area in Fig. 2 right) were determined using image analysis software, and the measured area was expressed in pixels. These values were further used to obtain normalization factors, which served for equalized comparisons of different band-pass widths.

3. Normalization factors were calculated by dividing the average of all the measured areas by the area measured for each filter pair.

4. The difference in the measured change in property for specimens exposed behind each pair of filters in the set was determined by deducting each measured value of a specific property. This presents the degradation attributed to the addition of shorter wavelength radiation transmitted by the shorter filter of the pair.

5. This difference was multiplied by the normalization factor for each filter pair and plotted versus the nominal (lower) cut-off wavelength of the respective filter pair to obtain the activation spectra (bar diagrams in results and discussion section). The wavelength values on the diagrams denote the transmittance value of the lower end of the particular spectral section.

\section{Results and discussion}

\section{Colour changes}

Figure 3 shows the contribution of the different colour parameters $\left(\Delta \mathrm{L}^{*}, \Delta \mathrm{a}^{*}\right.$, $\left.\Delta \mathrm{b}^{*}\right)$ to the overall colour changes $\left(\Delta \mathrm{E}^{*}\right)$ and their development during natural filtered exposure. $\Delta \mathrm{L}^{*}$ (lightness) and $\Delta \mathrm{a}^{*}$ values never exceeded 8 units and changed much less compared to $\Delta \mathrm{b}^{*}$ throughout the whole weathering period. Changes in lightness $\left(\Delta \mathrm{L}^{*}\right)$ are generally negative, which means that strips had darkened during the exposure. Similarly for all other colour parameters, the first 30 days of exposure affected only the top strips and only the UV light caused discoloration (Figs. 3, 4a, b). 

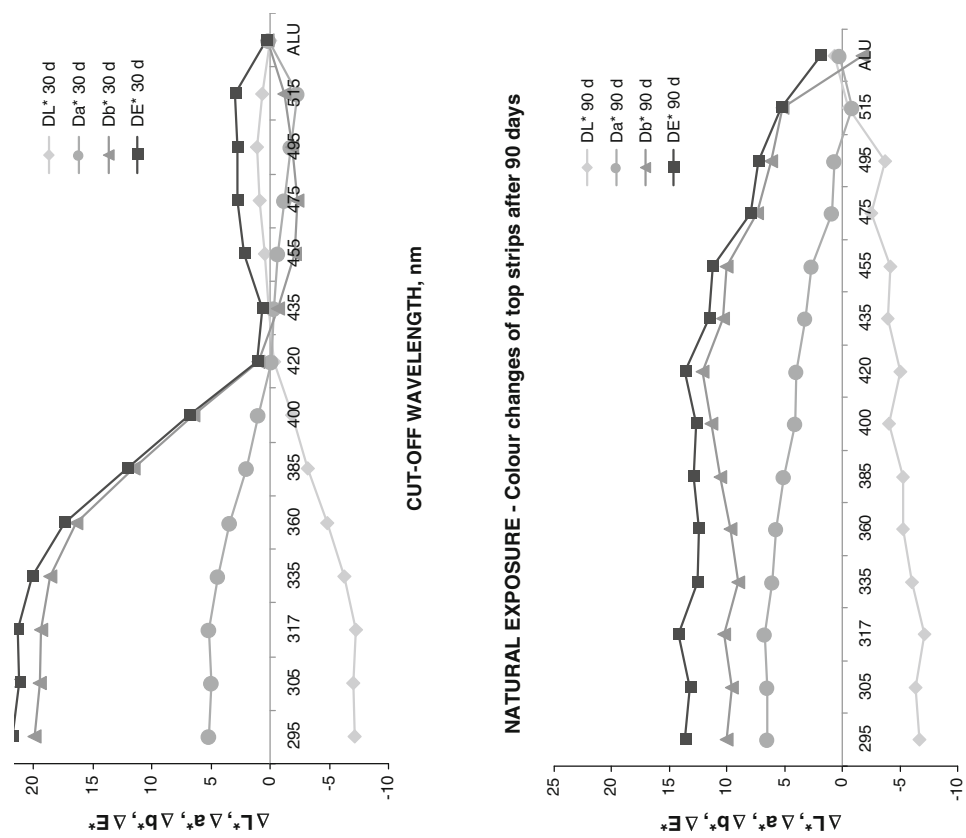

茪
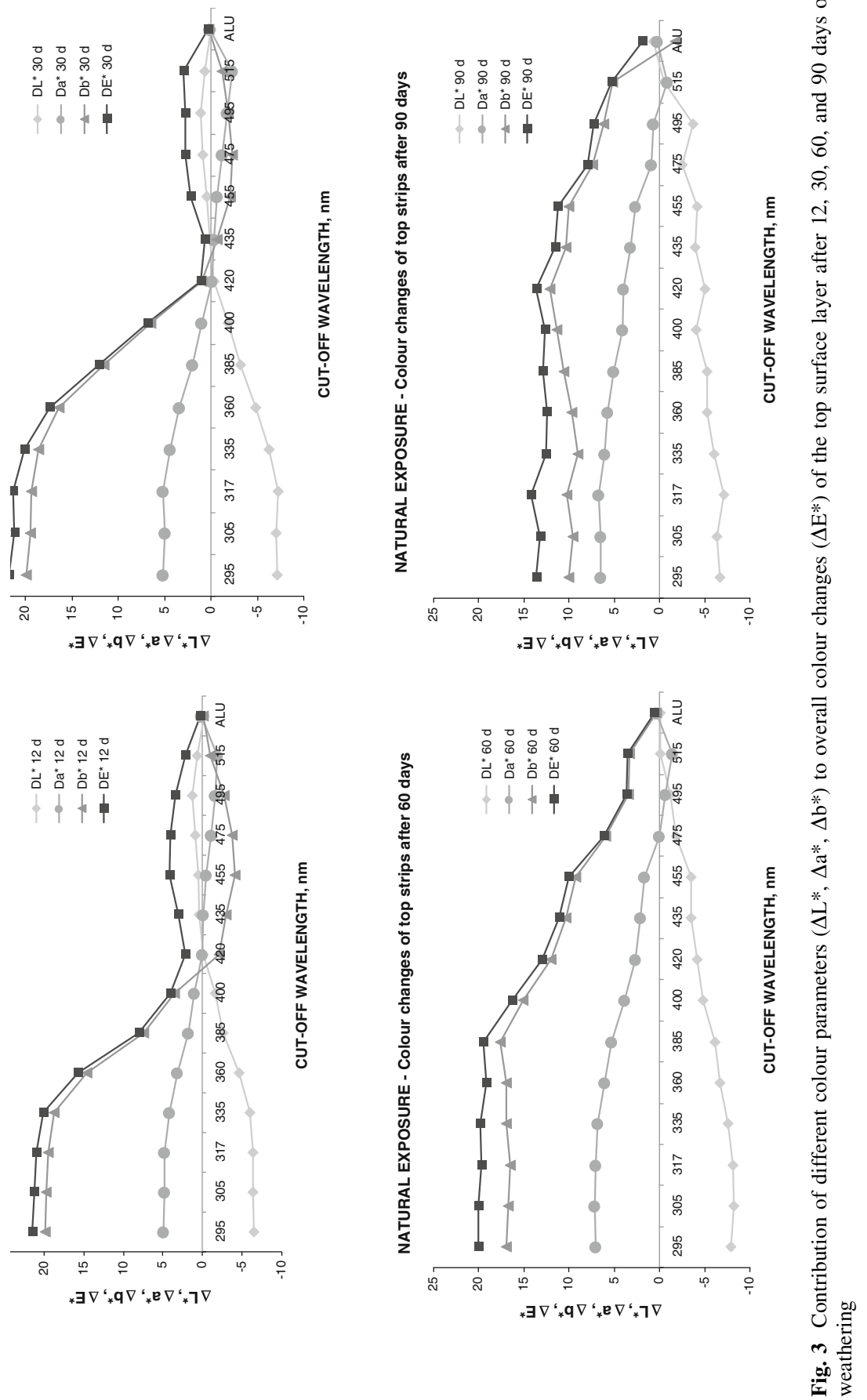

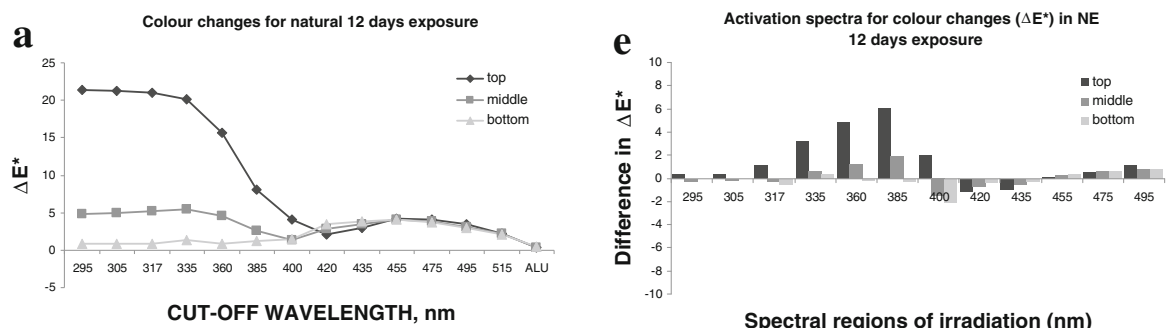

Spectral regions of irradiation $(\mathrm{nm})$
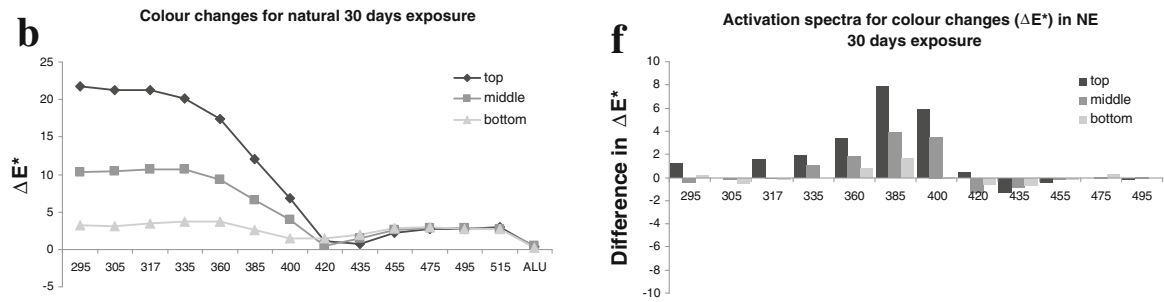

CUT-OFF WAVELENGTH, nm

Spectral regions of irradiation $(\mathrm{nm})$
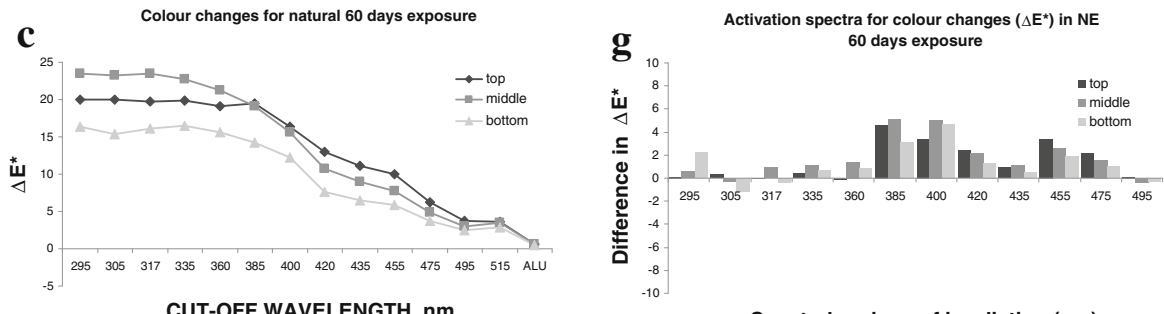

Spectral regions of irradiation $(\mathrm{nm})$
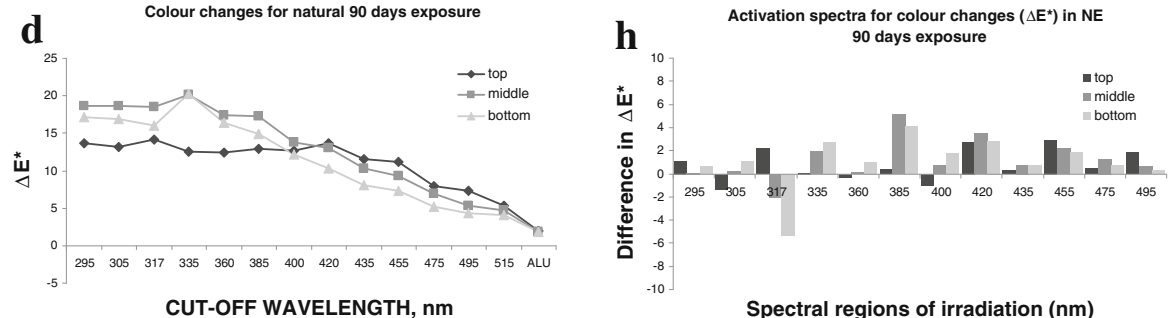

Fig. 4 Average colour changes $\Delta \mathrm{E}^{*}$ (a-d) and relative contribution of spectral bands to causing damage (activation spectra) (e-h) in the top, middle, and bottom strips during natural weathering

Even though the magnitude of changes did not increase after 30 days, the changes in middle and bottom strips started to resemble those of the top strips. In addition, visible light had a greater effect on discoloration (Fig. 4a-d). In the absence of bleaching due to leaching of degraded material which happens during full exposure, the strips exposed behind glass filters showed a good relationship between $\Delta \mathrm{E}^{*}$ and $\Delta \mathrm{b}^{*}$, indicating that colour changes are dominated by yellowing. Time dependence and depth profile of colour changes as well as corresponding activation spectra are therefore presented only for $\Delta \mathrm{E}^{*}$ (Fig. $4 \mathrm{a}-\mathrm{h}$ ). 
Generally, after short-term weathering (12 and 30 days of exposure, Fig. 4a, b), the changes were most pronounced in the top strips, much less in the middle strips $(80-160 \mu \mathrm{m}$ ), and were very small in the bottom strips (down to $240 \mu \mathrm{m}$ depth of surface). It seems that the UV light did not reach the bottom strip, since only the visible wavelengths caused an increase in $\Delta \mathrm{E}^{*}$ on all three strips (diagram in Fig. 4a). In contrast to the UV light, no distinctive depth profile was produced initially by visible light. Visible light was able to cause a photodegradation depth profile only during prolonged exposure (diagrams in Fig. 4c, d). This suggests that visible light penetrated much deeper than the UV light, immediately reaching the third strip, or that the topmost wood cells filtered out the detrimental UV effect in deeper surface layers.

The effect of visible light became more apparent with increasing exposure time as indicated by the shift in the $\Delta \mathrm{E}^{*}$ curves to the visible range (diagrams in Fig. 4c, d). Even when exposed only to "long" visible wavelengths (475-515 nm) for more than 60 days, all three strips showed $\Delta \mathrm{E}^{*}$ values in the range between 5 and 10, a distinctive colour change noticed by human eye (Sandermann and Schlumbom 1962b). The initial differentiation between the effect of UV and visible light, which was obvious as a sharp drop in the curves around $400 \mathrm{~nm}$ after 12 and 30 days, diminishes with prolonged exposure. Accordingly, the curves of $\Delta \mathrm{E}^{*}$ after 60 or 90 days showed a continuous development of discoloration over the entire range of the active spectrum. Therefore, the formerly habitual diversification of the light spectrum into two main portions, namely the UV region which is "active, degrading, detrimental in polymer degradation" and the "less efficacious visible light region" (Hon 1991), seems to be less evident. Kataoka et al. (2007), based on an experiment with monochromatic light, have already demonstrated that visible light could degrade wood. However, the results of the current study indicate that the transition between UV and visible portion of sunlight is gradual, and the measured changes were continuously developed into the depth and extended further into the visible region with duration of exposure. Prolonged exposures (60 and 90 days) reversed the order of discoloration profiles in the UV region, where the top layers had lower $\Delta \mathrm{E}^{*}$ values than the deeper surface layers. Indeed, after 90 days, both middle and bottom strips exhibited higher $\Delta \mathrm{E}^{*}$ values than the top one (Fig. $4 \mathrm{~d}$ ). As the top strips were not exposed to washing out of degraded products by liquid water, either some antagonistic processes developed in the shallow surface layer, or the bleaching of the top surface layer was caused by formation of some gaseous end products (Kalnins 1966). Further to colour measurements, physical appearance of earlywood bands of top strips looked paler and more translucent, while latewood bands looked darker.

Strips that were exposed under the aluminium foil exhibited some distortions, like slight bowing and shrinkage at the edges. However, the moisture content fluctuations were still within the hygroscopical range (i.e. without liquid water formation within the lumina or on the surfaces of the strips) and could have not influenced the colour changes (Fig. 4). The absence of colour changes under the aluminium foil indicated that discolouration was largely due to the effect of light. 
Activation spectra for colour changes

Activation spectra differed depending on time of exposure and depth from the surface. In the spectral region below $335 \mathrm{~nm}$, the contribution of different wavelengths to the overall colour changes was very small. This is a noteworthy finding, since previous studies indicated that the actinic effect of light progressively increased with reduction in wavelength.

Initially, there was a substantial contribution to colour changes by the wavelengths between 335 and $400 \mathrm{~nm}$, and the wavebands in the visible range of spectrum (above $420 \mathrm{~nm}$ ) contributed only to a very small extent to overall colour changes (Fig. 4e). The weathering period between 30 and 60 days represented a turning point during which the overall colour changes of the first strips reached their maxima, and $\Delta \mathrm{E}^{*}$ values started decreasing thereafter. At the same time, the contribution of the "transition" spectral wavelengths (385-435) gained significance, and the actinic effect of visible light (up to $515 \mathrm{~nm}$ ) proved to be ever more pronounced in all three layers as the duration of exposure increased.

Most pronounced colour changes $\left(\Delta \mathrm{E}^{*}\right)$ of middle strips $(80-160 \mu \mathrm{m})$ were caused by two separate light wavebands: the one between 385 and $435 \mathrm{~nm}$ (Fig. 4) and in the violet and blue visible wavelength region $(455-495 \mathrm{~nm}$ ) in the later stages of exposure. Wavelength sensitivity research of different polymeric materials usually resulted in one broader or narrower wavelength range responsible for photodegradation (Sandermann and Schlumbom 1962a; Andrady et al. 1996; Hu 1997; Andrady and Searle 1995; Suttie 2006; Kataoka et al. 2007). Nevertheless, similarly to the results of the present study, two distinctly separate spectral regions were detected when studying wavelength sensitivity of polycarbonate and polyamide 6 (Andrady et al. 1992; Hu 1998).

The bottom strips showed very small changes at the beginning of weathering. With prolonged exposure up to 30 days, however, they were also affected by the wavelengths in the range between 385 and $400 \mathrm{~nm}$. Longer exposure (up to 90 days) showed that the bottom strips changed colour almost as much as the upper ones (Fig. 4d). Practically, all wavelengths of light, from low UV to blue visible light, contributed to the discolouration of deeper surface layers to a lesser or greater extent. The peak in the region from 317 to $335 \mathrm{~nm}$, seen on the third strips after 90 days (Fig. 4h), deviated from the observed general trend and may be regarded as an artefact. The results of this study thus differ in this respect from those of former researchers (Sandermann and Schlumbom 1962a; Derbyshire and Miller 1981; Suttie 2006; Kataoka et al. 2007) probably due to differences in experimental conditions in various artificial and natural exposures.

Positive correlation between the penetration of light into sugi earlywood and the wavelength of the incident radiation shows that UV light penetrates shallower, mostly up to $150 \mu \mathrm{m}$, while visible light may penetrate even $400 \mu \mathrm{m}$ in depth (Kataoka et al. 2007). Even though it was not aimed to detect the exact depth of penetration of light into wood, this finding is important for the present work because it indicates that the surface layer studied here and which may be affected by visible light could be deeper than the thickness of strips used by 
Turkulin and coworkers (Derbyshire et al. 1995, 1996, 1997; Turkulin and Sell 2001; Turkulin et al. 2004). Furthermore, pronounced colour changes even $160 \mu \mathrm{m}$ from the surface detected in this work here are in accordance with the results of Kataoka et al. (2007), but directly contradict the results by Hon and Ifju (1978) who indicate that the depth of UV light penetration does not exceed $75 \mu \mathrm{m}$. Browne and Simonson (1957) reported that the penetration of UV light into wood is negligible, and therefore, the observed colour changes in deeper layers are the consequence of water-soluble degradation products brought by rain water. As there was no liquid water present in the current experiment, it is unlikely that migration of photodegradation products could have occurred. Finally, results of colour changes in the work here partially corresponded to those of Kataoka et al. (2007). Based on measurements on sugi earlywood, they suggest that surface treatments should be adjusted to protect wood from wavelengths up to $430 \mathrm{~nm}$, even though they detected that blue light wavelengths (434-496 nm) cause some bleaching of wood without chemical changes after photobleaching. Pronounced colour changes on fir radial surfaces caused by longer wavelengths were noticed (after 90 days of natural filtered weathering $\Delta \mathrm{E}^{*}>11$ for strips behind filters blocking light below $455 \mathrm{~nm}$, $\Delta \mathrm{E}^{*}>7$ for those behind filters at $495 \mathrm{~nm}$ ). The differences in colour changes may be attributed to differences in wood species, weathering conditions, and duration of exposure.

\section{Conclusion}

Natural exposure of thin strips of fir wood under a set of cut-off filters enabled the precise formulation of activation spectra for colour changes in various layers of a softwood surface and shed new light on the former generally accepted knowledge of wood photodegradation. Short-term exposure to sunlight (up to 30 days of natural exposure) caused colour changes that were very pronounced in the $80 \mu \mathrm{m}$ thick top layer of the surface, much less in the medium layers $(80-160 \mu \mathrm{m})$, and very small in the deepest studied layer (down to $240 \mu \mathrm{m}$ ).

Prolonged natural exposures (60 and 90 days) showed an unusual order in the discolouration profile, where the top layers attained decreasing $\Delta \mathrm{E}^{*}$ values (less than 20 units), while the deeper layers became darker than the very exposed surface. Even the deepest surface layers $(160-240 \mu \mathrm{m})$ became almost as dark as the superficial layer. This indicated that the photodegradation develops into a complex and dynamic process which must be studied over deeper layers of the surface and over exposure time.

In the spectral region below $335 \mathrm{~nm}$, the contribution of wavebands to the overall colour changes proved very small. Relatively narrow waveband of most active wavelengths caused the greatest proportion of colour changes (360-435 nm). However, it was confirmed that visible light of wavelengths up to $515 \mathrm{~nm}$ also contributed significantly to surface discolouration. With chronological development of exposure, the colour changes shifted ever deeper into the surface and further into the visible region of the spectrum. 
Acknowledgments Experimental work was executed at Empa-Swiss Federal Laboratories for Materials Science and Technology and University of Zagreb-Faculty of Forestry within the frame of the scientific projects Integrity and durability of wood surface and Finishing and modification of wood surface. The authors gratefully acknowledge the financial support of Swiss Federal Commission for Scholarships for Foreign Students, Croatian Ministry of Science, Education and Sports, COST and COST Action FP1006.

Open Access This article is distributed under the terms of the Creative Commons Attribution License which permits any use, distribution, and reproduction in any medium, provided the original author(s) and the source are credited.

\section{References}

Andrady AL (1997) Wavelength sensitivity in polymer photodegradation. In: Advances in polymer science, Springer, Berlin, pp 47-94

Andrady AL, Searle ND (1995) Photoyellowing of mechanical pulps. Part 2: activation spectra for light induced yellowing of newsprint paper by polychromatic radiation. Tappi J 78:131-138

Andrady AL, Searle ND, Crewdson LFE (1992) Wavelength sensitivity of unstabilized and UV stabilized polycarbonate to solar simulated radiation. Polym Degrad Stab 35:235-247

Andrady AL, Torikai A, Kobatake T (1996) Spectral sensitivity of chitosan photodegradation. J Appl Polym Sci 62:1465-1471

Browne FL, Simonson HC (1957) The penetration of light into wood. For Prod J 10:303-314

Chang ST, Wang SY, Cheng SS (1999) Red color enhancement of sugi (Cryptomeria japonica D.Don) heartwood by light irradiation. J Wood Sci 45:271-273

Chang ST, Wang SY, Cheng SS (2000) Environmental effects on the color of sugi (Cryptomeria japonica D.Don) heartwood. J Wood Sci 46:390-394

Derbyshire H, Miller ER (1981) The photodegradation of wood using solar irradiation. Part 1. Effects on the structural integrity of thin wood strips. Holz Roh Werkst 39:341-350

Derbyshire H, Miller ER, Turkulin H (1995) Investigations into the photodegradation of wood using microtensile testing. Part 1: the application of microtensile testing to measurement of photodegradation rates. Holz Roh Werkst 53:339-345

Derbyshire H, Miller ER, Turkulin H (1996) Investigations into the photodegradation of wood using microtensile testing. Part 2: an investigation of the changes in tensile strength of different softwood species during natural weathering. Holz Roh Werkst 54:1-6

Derbyshire H, Miller ER, Turkulin H (1997) Investigations into the photodegradation of wood using microtensile testing. Part 3: the influence of temperature on photodegradation rates. Holz Roh Werkst 55(5):287-291

Evans PD (1988) A note on assessing the deterioration of thin wood veneers during weathering. Wood Fiber Sci 20(4):487-492

Evans PD, Urban K, Chowdhury MJA (2008) Surface checking of wood is increased by photodegradation caused by ultraviolet and visible light. Wood Sci Technol 42:251-265

Hon DNS (1991) Photochemistry of wood. In: Hon DN-S, Shiraishi N (eds) Wood and cellulosic chemistry. Chapter 11:525-555. Marcel Dekker, New York

Hon DNS, Ifju G (1978) Measuring penetration of light into wood by detection of photoinduced free radicals. Wood Sci 11(2):118-127

Hu X (1997) Wavelength sensitivity of photo-oxidation of polyethylene. Polym Degrad Stab 55:131-134

Hu X (1998) Wavelength sensitivity of photo-oxidation of polyamide 6. Polym Degrad Stab 62:599-601

Jacques LFE (2000) Accelerated and outdoor/natural exposure testing of coatings. Prog Polym Sci 25:1337-1362

Kalnins MA (1966) Surface characteristics of wood as they affect durability of finishes. Part II. Photochemical degradation of wood. U.S Forest Service. Res Pap FPL 57:23-57

Kämpf G, Sommer K, Zirngiebl E (1991) Studies in accelerated weathering. Part 1. Determination of the activation spectrum of photodegradation in polymers. Prog Org Coat 19:69-77

Kataoka Y, Kiguchi M, Williams RS, Evans PD (2007) Violet light causes photodegradation of wood beyond the zone affected by ultraviolet region. Holzforschung 61:23-27 
Mitsui K (2010) Acetylation of wood causes photobleaching. J Photoch Photobio B 101:210-214

Raczkowski J (1980) Seasonal effects on the atmospheric corrosion of spruce micro-sections. Holz Roh Werkst 38:231-234

Sandermann W, Schlumbom F (1962a) Über die Wirkung gefilterten ultravioletten Lichts auf HolzErste Mitteilung: photometrische und chromatographische Untersuchungen an Holzmehlen. Holz Roh Werkst 20(7):245-252

Sandermann W, Schlumbom F (1962b) Über die Wirkung gefilterten ultravioletten Lichts auf HolzZweite Mitteilung: Änderung von Farbwert und Farbempfindung an Holzoberflächen. Holz Roh Werkst 20:285-291

Scott KP (2001) Shedding some numbers on light. Mater Technol News 30(64):1-7

Suttie E (2006) Photodegradation of wood-Defining activation spectra for colour change. In: Fifth international woodcoatings congress Enhancing service life. October 17-18 2006, Prague, The Chech Republic

Tolvaj L, Mitsui K (2010) Correlation between hue angle and lightness of light irradiated wood. Polym Degrad Stab 95:638-642

Turkulin H (1996) Photodegradation of exterior timber building components. Dissertation, University of Zagreb

Turkulin H, Sell J (2001) Investigations into the photodegradation of wood using microtensile testing. Part 4: tensile properties and fractography of weathered wood. Holz Roh Werkst 60:96-105

Turkulin H, Derbyshire H, Miller ER (2004) Investigations into the photodegradation of wood using microtensile testing. Part 5: the influence of moisture on photodegradation rates. Holz Roh Werkst 62:307-312

Turkulin H, Arnold M, Richter K, Strub E, Jirouš Rajković V, Mihulja G (2006) Hydrophobic treatment for improvement of wood surface durability. In: Fifth international woodcoatings congress Enhancing service life, October 17-18 2006 Prague, The Chech Republic

ASTM G178-09 Standard Practice for Determining the Activation Spectrum of a Material (Wavelength Sensitivity to an Exposure Source) Using the Sharp Cut-On Filter or Spectrographic Technique 